\section{Construtos teóricos de Paulo Freire norteando as estratégias de promoção à amamentação}

\section{Using the theoretical constructs of Paulo Freire to guide breastfeeding promotion strategies}

Francisca Márcia Pereira Linhares 1

Cleide Maria Pontes 2

Mônica Maria Osório 3

\begin{abstract}
Objectives: to reflect on the use of the theoretical constructs of Paulo Freire, dialogue, ethics and problematization for the promotion of breastfeeding involving the woman's social network.

Methods: a theoretical trial was carried out, consisting of a logical, argumentative and critical exposition, guided by Freire's thinking applied to breastfeeding, as a way of providing new approaches to actions promoting this practice.

Results: the development of educational actions based on a theoretical point of reference may be able to guide the implementation of breastfeeding promotion strategies, based on the critical reflection of the practice of liberationist pedagogy, centered on dialogical, problematizing, ethical knowledge, in the context of the reality of all the actors involved in maternal breastfeeding.

Conclusions: the theoretical constructs of Paulo Freire value popular knowledge and the exchange of know-how in the establishment of a relation of trust between health professionals and pregnant/nursing women and their family members during actions to promote maternal breastfeeding.
\end{abstract}

Key words Breastfeeding, Health promotion, Health education

\section{Resumo}

Objetivos: refletir sobre a inserção dos construtos teóricos de Paulo Freire, o diálogo, a ética e a problematização, na promoção da amamentação, envolvendo a rede social da mulher.

Métodos: ensaio teórico que consiste em exposição lógica, argumentativa e crítica, conduzida pelo pensamento freireano integrado ao fenômeno da amamentação para subsidiar novos caminhos que poderão permear as ações promotoras desta prática.

Resultados: o desenvolvimento de ações educativas alicerçadas em um referencial teórico poderá guiar a implementação de estratégias na promoção da amamentação, baseadas na reflexão crítica da prática pedagógica libertadora, centrada no saber dialógico, problematizador e ético, no contexto da realidade de todos os atores envolvidos com o aleitamento materno.

Conclusões: os construtos teóricos de Paulo Freire valorizam o saber popular e a troca de saberes no estabelecimento de uma relação de confiança entre os profissionais de saúde e as gestantes/nutrizes e familiares, durante as ações de promoção ao aleitamento materno.

Palavras-chave Amamentação, Promoção em saúde, Educação em saúde 


\section{Introdução}

Paulo Freire, nascido em 19 de setembro de 1921 em Recife, Pernambuco, foi um educador que desenvolveu um método inovador de alfabetização de adultos na área da educação popular. É considerado um dos pensadores mais notáveis na história da pedagogia mundial. Tornou-se uma inspiração para gerações de professores, especialmente na América Latina e na África. Seus pensamentos delinearam a Pedagogia da Libertação, relacionada à visão marxista do terceiro mundo e na mobilização das classes oprimidas no sentido do exercício da educação como direito de cidadania, e do ser político e social na construção de sua história de vida. ${ }^{1}$

A proposta pedagógica de Paulo Freire recomenda uma ação dialogal entre educadores e educandos para a construção do conhecimento na qual é dada a eles a oportunidade conhecer sua própria história de vida e intervir na sociedade de maneira consciente. O seu método é constituído de três etapas: investigação, tematização e problematização. ${ }^{2}$

$\mathrm{Na}$ etapa de investigação, professor e aluno, conjuntamente, buscam as palavras geradoras e temas mais significativos, dentro do seu universo vocabular. Essas palavras significam palavras-chave do vocabulário dos alunos. Elas devem sugerir situações de vida comum e significativas para os atores envolvidos no processo de ensino e aprendizagem. Emergem durante as conversas informais, nas quais o educador observa os vocábulos mais usados, selecionando palavras que servirão de base para as lições. Depois de composto o universo das palavras geradoras, estas são apresentadas em cartazes com imagens. ${ }^{2}$

Então, inicia-se uma discussão nos círculos de cultura, visando promover o processo de ensino aprendizagem por meio de um debate sobre questões diversas exercitando o diálogo. Os participantes formam uma roda de modo que todos têm oportunidade de se verem e discutirem um tema da cultura. Nesta roda, não há professor e sim um moderador das discussões. ${ }^{2}$

A etapa de tematização é o momento da tomada de consciência do mundo, analisando os significados sociais dos temas e palavras. Na problematização, o professor e educando buscam uma visão crítica partindo para a transformação do contexto vivido. ${ }^{2}$

No método de Paulo Freire, o ponto de partida para o processo educacional está vinculado à vivência dos sujeitos, seus contextos, problemas e angustias, além de estimular à colaboração, a decisão, a participação e a responsabilidade social e política. O conhecimento é construído coletiva- mente, mediado pelo diálogo e articulado com a experiência de vida. É uma prática integradora e interativa, pois os sujeitos estão abertos para o novo e sempre dispostos a algo mais para interpretar, descobrir, aprender, dizer e compartilhar. ${ }^{3}$

$\mathrm{O}$ pensamento freireano, norteado por constructos teóricos, revela que o ato educativo deve ser um ato de recriação e de ressignificação de significados para o alcance da libertação social e política. ${ }^{4}$ Dessa maneira, o objetivo desse estudo é refletir sobre a inserção dos construtos teóricos de Paulo Freire, o diálogo, a ética e a problematização, na promoção da amamentação, envolvendo a rede social da mulher.

\section{Métodos}

Este estudo é um ensaio teórico que consiste na exposição lógico-reflexiva com ênfase na argumentação e interpretação pessoal ${ }^{5}$ sobre o pensamento freireano integrado ao fenômeno da amamentação. Para isso, o material consultado foi submetido a etapas de leitura científica: 6 reconhecimento, objetivando localizar fontes preliminares sobre o tema; seletiva, localizando as informações pertinentes ao estudo; crítico-reflexiva, buscando os significados e as ideias principais; e interpretativa, articulando os construtos teóricos de Paulo Freire na promoção da amamentação.

\section{Reflexões teóricas dos construtos de Paulo Freire no contexto da amamentação}

A preocupação com a promoção da amamentação no âmbito da saúde pública não é um fato recente. Um dos primeiros registros é o Código de Hamurabi, elaborado por volta de 1800 a.c. que apresenta descrições detalhadas sobre esta prática, estabelecendo as normas para as mulheres que amamentavam o próprio filho e para as amas-de-leite, mulheres que davam de mamar a crianças de outras mães. ${ }^{7}$

$\mathrm{Na}$ Grécia, entre os anos de 460 a 370 a.c., Hipócrates ressaltou os benefícios da amamentação como dieta higiênica, mostrando que a mortalidade infantil era maior em crianças que não eram amamentadas. Os filósofos da época eram a favor da amamentação e posicionavam-se contra a prática do aleitamento em amas-de-leite. Esse fato deu origem ao Código Teodosiano que continha as estratégias de intervenções políticas que moldavam o comportamento feminino no século $\mathrm{V}$, em Roma. ${ }^{8}$

$\mathrm{O}$ incentivo à prática do aleitamento materno continuou com o advento do cristianismo, principal- 
mente nas épocas de Constantino (315 d.c.), Carlos Magno e Inocêncio III (1198 d.c.). ${ }^{9}$ Nos séculos XII a XIII, entretanto, a igreja exercia um controle rígido sobre o comportamento da mulher. As nutrizes e as crianças eram colocadas em situação de inferioridade na sociedade. As mulheres que amamentavam eram consideradas sujas e o ato de aleitar, animalesco e comprometedor da beleza física e da sexualidade. Esse pensamento perdurou até o final do século XVII. 8

No século XVIII, entre outros fatores, o desmame precoce contribuiu para que a mortalidade infantil chegasse a índices elevados, ocasionando uma ameaça econômica por falta de escassez de mão de obra, em consequência do despovoamento. A criança, antes negligenciada, assumiu um valor mercantil e o Estado necessitava da participação feminina para conservá-la viva. ${ }^{8}$

No final do século XIX, a mortalidade infantil nas classes mais pobres continuava elevada. Para modificar esse cenário, no contexto da industrialização, urbanização e a emancipação feminina, um dos desafios foi a promoção de uma alimentação adequada para as crianças. 10 Neste período a indústria de produtos alimentícios passou a estimular o uso de leite artificial em substituição ao leite materno, ressaltando a imagem do produto perfeito que iria facilitar a vida da mulher.

A propaganda indiscriminada, o apoio dos profissionais de saúde e o ingresso da mulher no mercado de trabalho contribuíram para a introdução do leite artificial e consequente diminuição da prática do aleitamento materno neste século XIX.11

A partir dos registros citados, percebemos que desde as civilizações mais antigas, a promoção da amamentação vem constituindo um processo social e cultural com etapas de incentivo intercaladas por desestímulos à prática do aleitamento. Estas últimas são decorrentes das influências e interesses socioeconômicos que visam controlar e impor posturas e comportamentos pré-estabelecidos.

Com intuito de reverter o desmame precoce, o Governo Federal do Brasil, a partir de 1981, implantou o Programa Nacional de Incentivo ao Aleitamento Materno, por meio do Instituto Nacional de Alimentação e Nutrição em convênio com o Fundo das Nações Unidas para a Infância. ${ }^{12}$ A Organização Mundial da Saúde, na 54 Assembleia Mundial da Saúde, ressaltou a necessidade do incentivo ao aleitamento materno exclusivo e do desenvolvimento de estratégias de promoção, proteção e apoio à amamentação, com a finalidade de aumentar a prevalência desta prática. ${ }^{13}$ Neste sentido, o Ministério da Saúde viabilizou cursos de capacitação aos profissionais de saúde em serviço, a criação da estratégia Iniciativa Hospital Amigo da Criança ${ }^{14}$ e a Iniciativa Unidade Básica Amiga da Amamentação. 15

As propostas pedagógicas do Ministério da Saúde para a promoção da amamentação vêm mudando nos últimos anos, passando de um modelo verticalizado para a utilização de metodologias ativas. $12,15,16$ Nesse sentido, o governo federal instituiu a Estratégia Amamenta e Alimenta Brasil objetivando:

\footnotetext{
“... qualificar profissionais da saúde para apoiar o fortalecimento, planejamento, implementação e avaliação de ações de promoção, proteção e apoio ao aleitamento materno e alimentação complementar saudável nas Unidades Básicas de Saúde, de forma contínua, considerando a educação permanente em saúde, com base nos princípios da educação crítico-reflexiva."16 (p.6).
}

Apesar dessas mudanças, o desmame precoce ainda é uma prática frequente 17 e os profissionais de saúde se transformaram em instrumentos de produção de subjetividade e anulam a capacidade criativa dos usuários, expressando uma prática educativa de transmissão vertical. 18

Para muitos profissionais de saúde, a troca de saberes entre os usuários do serviço é uma prática inovadora e pouco utilizada. Talvez isto seja devido às próprias políticas excludentes, nas quais o indivíduo não foi estimulado a participar do seu processo educativo ou à falta de disposição dos profissionais em reconhecer e legitimar estes avanços dentro da prática de educação em saúde. 19 Portanto, existe a necessidade de encontrar caminhos que possam envolver todos os atores participantes nas estratégias de promoção da amamentação, levando em consideração a sua cultura, hábitos e crenças.

A promoção da amamentação deve ser guiada por construtos que norteiam a educação popular, privilegiando as experiências dos sujeitos envolvidos e estimulando as mudanças individuais e coletivas. A educação popular baseia-se no enfoque críticoreflexivo, reconhecendo o caráter histórico, social, político e econômico dos sujeitos e, ao mesmo tempo, buscando romper o modelo normatizador. Para isso, metodologias que estimulam a participação e o empoderamento dos atores devem ser utilizadas na busca de transformações sociais, segundo a Teoria de Paulo Freire. ${ }^{3}$

Esta teoria não é simplesmente uma técnica pedagógica desenvolvida para alfabetizar adultos, e sim, um posicionamento teórico filosófico funda- 
mentado em vários construtos, entre eles, o diálogo, a ética e a problematização, essenciais na relação de comunicação e intercomunicação entre os sujeitos. ${ }^{3}$ Esses referenciais podem modificar a assistência à mulher e à família durante as fases do ciclo reprodutivo, incluindo a amamentação.

\section{Diálogo}

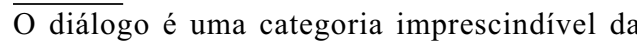
teoria freireana e constitui-se de ação e reflexão, sendo:

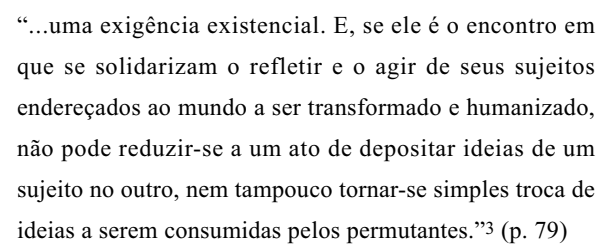

Entretanto, quando se coloca o tema aleitamento materno em discussão, na maioria das vezes, percebemos que a gestante e/ou a nutriz e sua família não interagem com o saber técnico-científico do profissional de saúde envolvido com esta prática.

As ações educativas para a promoção do aleitamento materno ainda são caracterizadas pelo autoritarismo e o excesso de informação. As gestantes e nutrizes e seus familiares, conscientes de suas reais possibilidades e desejos, não veem espaço para contrariar a opinião dos profissionais de saúde, mas quando são estimulados à verbalização, mostram-se acessíveis ao diálogo. 20

Essa passividade geralmente acontece quando a ação educativa é permeada pelo ensino tradicional ou bancário que é guiado pelo autoritarismo e o conhecimento popular dos educandos não é valorizado.3,21 Dessa forma, percebemos que a promoção do aleitamento materno vem sendo mediada pela educação tradicional, caracterizada pelo monólogo, no qual os profissionais de saúde são os detentores do saber e a mulher um ser passivo, cujo conhecimento é imposto e manipulado.

No contexto do aleitamento materno os profissionais de saúde não são donos da verdade e nem proprietários do saber. Portanto, a promoção da amamentação não pode ser uma prática educativa de depósito de conteúdos, apoiada na concepção de que as pessoas não têm conhecimento. A mulher e sua família são portadores de experiências e de um saber que precisam ser legitimados por meio do diálogo. 4

O objetivo do diálogo não é o de informar, mas transformar os saberes existentes por meio do processo de conscientização 22 durante todas as ações de promoção do aleitamento materno. Para isso, é preciso conhecer os indivíduos, considerando as suas condições cultural, social e política, envolvendo-os no processo educativo participativo que se contrapõe a ação educativa verticalizada. ${ }^{23}$

Durante a comunicação dialógica, ${ }^{21}$ os atores envolvidos no processo do aleitamento materno devem refletir o que sabem e o que não sabem sobre amamentação, novos conceitos são introduzidos e mudanças concretas da realidade podem acontecer por meio da mobilização e organização coletiva.

$\mathrm{Na}$ promoção da amamentação, as trocas de experiências, opiniões e expressão de dúvidas entre os participantes envolvidos são necessárias. Os profissionais de saúde devem promover a escuta ativa, no sentido de proporcionar à mulher a oportunidade de expressar seus saberes, provenientes do convívio e experiências com outras mulheres, família e comunidade, para que ela assuma com mais segurança a prática de amamentar.

Corroborando com os pensamentos acima, um estudo utilizando a pedagogia participativa possibilitou a reflexão de que cada mulher é dotada de especificidades próprias e que as ações de aconselhamento devem ser permeadas pelos princípios da humanização. 24

No compartilhamento de novos saberes, o profissional de saúde deverá mediar o debate entre o homem, a natureza e a cultura. Este diálogo somente é possível entre aqueles que possuem interesses que se convergem e é um instrumento legal de mobilização do homem contra todo e qualquer tipo de exploração, opressão e desrespeito aos direitos humanos. ${ }^{3}$

No entanto, apesar dos esforços para mudança de paradigma nas estratégias de promoção da amamentação, o aleitamento materno ainda é focado apenas na abordagem unidirecional, sem considerar os aspectos políticos, sociais e culturais que o envolve. A sociedade defende os direitos da criança, esquecendo que a mulher nutriz tem o direito de decidir como alimentar o seu filho, e os profissionais de saúde, na busca do alcance do sucesso das intervenções, automatizam suas ações em detrimento do diálogo, tornando a assistência desumanizada. 25

O diálogo entre os profissionais, a mulher/nutriz e a sua rede social é um construto que pode alavancar o entendimento do manejo da prática do aleitar e de como se portar diante de dificuldades que podem surgir, durante todo o processo da amamentação.

\section{Problematização}

A problematização consiste em discutir questões que emergem de situações que fazem parte do coti- 
diano dos sujeitos. Esta abordagem inicia-se à medida que eles identificam sua realidade, dificuldades e situações-limites referentes às formas de se relacionar com o mundo, buscando caminhos e possibilidades de enfrentamento. Logo, parte-se do princípio de que as pessoas têm diferentes maneiras de ver um mesmo contexto. ${ }^{2}$

No momento da construção do pensamento crítico, o educador deve conhecer o universo do vocabulário dos educandos. A indagação é a condição primordial para estimular o desejo de conhecer e buscar esclarecimento, superando assim o pensamento ingênuo, alienado/alienante. Quanto mais o sujeito pergunta, mais é estimulado a questionar sobre a temática abordada com situações do seu contexto social instigando a formação do seu próprio pensamento. 3,26

Ao apreender a ação educativa sobre aleitamento como ato político, os profissionais de saúde oportunizam o acesso às informações sobre esta prática por meio de sua disponibilidade e capacidade em garantir uma escuta ativa a cada mãe. Esta estratégia pode assegurar a mulher o suporte necessário, considerando os seus limites e possibilidades, como também o direito de decidir sobre o processo da amamentação. 27,28

As ações educativas na promoção da amamentação devem ser muito mais do que um processo de treinamento ou domesticação. Estas ações buscam superar as práticas que se limitam à transferência de informações, uma vez que proporcionam a participação ativa por meio do estímulo do pensamento crítico sobre a realidade, na qual emerge a construção do conhecimento no confronto de ideias, levantamento de hipóteses e a relação entre os sujeitos. 4,29

A comunicação se faz presente quando acontece de maneira convergente e oportuniza os participantes a expor suas dificuldades, dúvidas e sentimentos. Esta verbalização não deve ser percebida pelos profissionais de saúde como atitudes de fragilidade e sim como expressão de experiências e saberes. Dessa maneira, é necessário valorizar a comunicação efetiva, a escuta ativa e a atitude compreensiva neste processo de construção coletiva. 4

O construto da problematização discutido por Paulo Freire é propicio para ser usado no contexto da amamentação, pois estimula os atores envolvidos a compreender o mundo, fundamental para que a mulher/nutriz seja acolhida por todos os atores de sua rede social.

\section{Ética}

A prática e a teoria freireana fundamentam-se em uma ética inspirada na relação de respeito e sem autoritarismo:

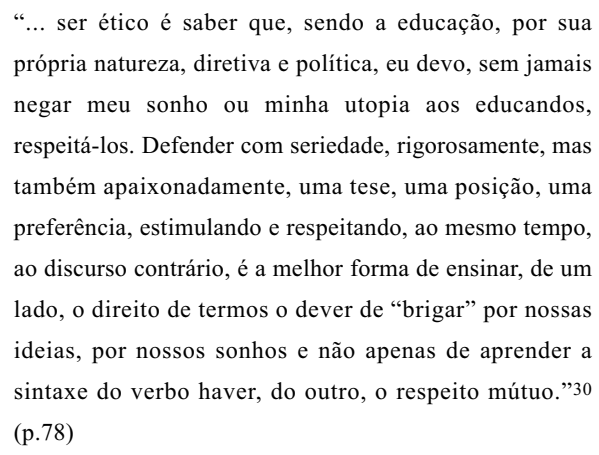

A formação ética acontece quando professor e aluno lutam por uma educação transformadora, dialógica e conscientizadora, engajados no processo da construção do conhecimento; todos ensinam e todos aprendem ligados às próprias experiências sociais e culturais, percebendo sua realidade criticamente e construindo o seu conhecimento por intermédio do diálogo. 23

Para Freire, a ética é a própria essência do ato educativo, na qual os saberes e a cultura do educando devem ser respeitados e a descriminação rejeitada, de modo que, as ações educativas não podem ficar alheias às diferenças individuais. ${ }^{4} \mathrm{Com}$ base nesta premissa, percebemos que um dos desafios a ser enfrentado pelos profissionais de saúde, na promoção da amamentação, é o de não transformar a experiência educativa em um treinamento sistemático e conteudista. Portanto, ao ensino dos conteúdos deve ser atrelado à formação moral dos educandos. 31

Na promoção da amamentação, uma ação educativa ética é caracterizada pela postura do profissional de saúde em assumir sua função de educador com responsabilidade, proporcionando um clima democrático aos atores envolvidos. A mulher e sua rede social devem ser compreendidas como sujeitos ativos no processo de aprendizagem. ${ }^{4}$ Os profissionais de saúde respeitando e entendendo como vivem os seres humanos não impõem seus conhecimentos. Conhecer a realidade significa investigar, pesquisar, desvelar e interagir com o mundo dos sujeitos. ${ }^{3}$

No período da amamentação existe uma apropriação social do corpo feminino que ressalta a maternidade como dever, responsabilidade e resignação. Por conseguinte, na maioria das vezes, as mulheres manifestam a conformação de seus corpos como corpo-função, apenas de nutrir o seu filho. 32 Para os profissionais de saúde, não basta entender os signifi- 
cados do aleitamento materno. Eles devem reconhecer o direito de escolha da mulher e respeitar sua decisão de querer ou não amamentar. Este comportamento ajudará a mulher a ser respeitada na tomada de decisão consciente. ${ }^{23}$

Na concepção freireana não haverá diálogo se não existir amor e respeito ao saber dos homens, e este somente será possível nas relações que não se buscam o poder. Para respeitar as diferenças é necessário aceitar as limitações e não ter uma postura de superioridade. Se o educador não reconhece os saberes construídos pelos sujeitos, a comunicação torna-se um monólogo, colocando-o como único portador do conhecimento. ${ }^{21}$ Dessa maneira, a interlocução deve acontecer durante todo o processo da amamentação.

\section{Considerações finais}

A utilização da proposta pedagógica recomendada por Paulo Freire, a partir destas categorias epistemológicas, nas quais o diálogo, a ética e a problematização se interagem, é indispensável no processo de construção das estratégias de promoção à amamentação. Esta proposta ajudará os profissionais de saúde a estabelecerem relacionamento de confiança

\section{Referências}

1. Souza AI. Paulo Freire: Vida e obra. São Paulo: Expressão Popular; 2001.

2. Freire P. Educação como prática de liberdade. 34 ed. Rio de Janeiro: Paz e Terra; 2011.

3. Freire P. Pedagogia do oprimido. 50 ed. Rio de Janeiro: Paz e Terra; 2011.

4. Freire P. Pedagogia da autonomia: saberes necessários à prática educativa. 43 ed. São Paulo: Paz e Terra; 2011.

5. Severino AJ. Metodologia do trabalho cientifico. 23 ed. São Paulo: Cortez; 2007.

6. Cervo AI, Bervian PA. Metodologia científica. 5 ed. São Paulo: Prentice Hall; 2002.

7. Ichisato SMT, Shimo AKK. Revisando o desmame precoce através de recortes da história. Rev Latino Am Enferm. 2002; 10 (4): 578-85.

8. Badinter E. Um amor conquistado: o mito do amor materno. Rio de Janeiro: Nova Fronteira; 1985.

9. Vinagre RD, Diniz EMA, Vaz FAC. Leite humano: um pouco de sua história. Pediatria (São Paulo) 2001; 23 (4): 340-5. 10. Lo CW, Kleinman RE. Infant formula, past and future: opportunities for improvement. Am J Clin Nutr. 1996; 63: 646-50. 11. Rea MF. Substitutos do leite materno: passado e presente. Rev. Saúde. Públ. 1990; 24 (3): 241-9.

12. Brasil. Ministério da Saúde e Instituto Nacional de Alimentação e Nutrição. Ações Integradas de Promoção da com os atores envolvidos, por meio de uma comunicação dialógica, levando a mulher e sua rede social a refletir e compreender a complexidade do processo da amamentação, suas nuances e dificuldades. Possibilitará também uma reflexão de que os protagonistas desta prática, a mulher e a família possuem conhecimento, valores, princípios e sentimentos e, ao mesmo tempo, o entendimento de sua responsabilidade em transformar a realidade a partir de uma ação consciente e reflexiva.

Os princípios freireanos contidos nesta proposta deverão permear as ações educativas para promoção da amamentação, no sentido de instrumentalizar a mulher e sua rede social, no pré-natal, puerpério e puericultura, quanto aos conhecimentos e apoios necessários, garantindo-lhe o direito de decisão consciente de amamentar seu filho.

Para isso, o maior desafio no desenvolvimento desta proposta, é considerar a interação entre os aspectos biológicos, emocionais, psicológicos, familiares, econômicos, políticos, sociais e culturais, inerentes ao processo do aleitamento materno, que necessita de adaptação a cada realidade, além de ações conjuntas entre gestores, profissionais de saúde, mulheres e familiares.
Saúde da Criança. Política Nacional de Incentivo ao Aleitamento Mateno. Brasília, DF; 1981.

13. WHO (World Health Organization). Global strategy for infant and young child feeding. Geneva; 2001.

14. Brasil. Ministério da Saúde. Iniciativa Hospital Amigo da Criança (IAHC). Brasília, DF; 2008.

15. Brasil. Ministério da Saúde. Manual de capacitação de equipes de unidades básicas de saúde na iniciativa básica amiga da amamentação (IUBAAM). Brasília, DF; 2003.

16. Brasil. Ministério da Saúde. Estratégia Amamenta e Alimenta Brasil. Brasília, DF; 2013.

17. Kaufmann CC, Albernaz EP, Silveira RB, Silva MB, Mascarenhas MLW. Alimentação nos primeiros três meses de vida dos bebês de uma coorte na cidade de Pelotas, Rio Grande do Sul. Rev Paul Pediatr. 2012; 30 (2): 157-65.

18. Pinafo E, Nunes EFPA, González AD, Garanhani ML. Relações entre concepções e práticas de educação em saúde na visão de uma equipe de saúde da família. Trab Educ Saúde. 2011; 9(2): 201-21.

19. Fernandes MCP, Backes VMS. Educação em saúde: perspectivas de uma equipe da Estratégia Saúde da Família sob a óptica de Paulo Freire. Rev Bras Enferm. 2010; 63: (4) $567-73$

20. Oliveira MIC, Souza IEO, Santos EM, Camacho LAB. Avaliação do apoio recebido para amamentar: significados de mulheres usuárias de unidades básicas de saúde do 
Estado do Rio de Janeiro. Ciênc Saúde Coletiva. 2010; 15 (2): 599-608.

21. Freire P, Shor I. Medo e ousadia: o cotidiano do professor. 12 ed. Rio de Janeiro: Paz e Terra; 2008.

22. Freire P. Educação e mudanças. 30 ed. Rio de Janeiro: Paz e Terra; 2007.

23. Alves VS. Um modelo de educação em saúde para o programa saúde da família: pela integralidade da atenção e reorientação do modelo assistencial. Interface Comun Saúde Educ. 2005; 9 (16): 39-52.

24. Moreira PL, Fabbro, MRC. Utilizando técnicas de ensino participativas como instrumento de aprendizagem e sensibilização do manejo da lactação para profissionais de enfermagem de uma maternidade. Acta Paul Enferm. 2005; 18 (3): 627-37.

25. Takushi SAM, Tanaka AC, Gallo PR, Machado MAM. Motivação da gestante para o aleitamento materno. Rev Nutr. 2008; 21 (5): 491-502.

26. Alvim NAT, Ferreira, MA. Perspectiva problematizadora da educação popular em saúde e a enfermagem. Texto Contexto Enferm. 2007; 16 (2): 315-9.
27. Faleiros FTV, Trezza ERC, Carandina L. Aleitamento materno: fatores de influência na sua decisão e duração. Rev Nutr. 2006; 19 (5): 623-30.

28. Souza SNDH, Mello DF, Ayres JRCM. O aleitamento materno na perspectiva da vulnerabilidade programática e do cuidado. Cad Saúde Pública. 2013; 29 (6): 1186-94.

29. Sfredo J, Ecco I. O conhecimento na pedagogia freireana como suporte teórico para a educação escolar formal. Revista Eletrônica "Fórum Paulo Freire". 2006; 2 (2): 1-12.

30. Freire P. Pedagogia da esperança: um reencontro com a Pedagogia do oprimido. 9 ed. Rio de Janeiro: Paz e Terra; 2002.

31. Sobral FR, Campos CJG. Utilização de metodologia ativa no ensino e assistência de enfermagem na produção nacional: revisão integrativa. Rev Esc Enferm USP. 2013; 46 (1): 208-18.

32. Nakano AMS. As vivências da amamentação para um grupo de mulheres: nos limites de ser "o corpo para o filho" e de ser "o corpo para si" Cad Saúde Pública. 2003; 19 (2): 35563.

Recebido em 26 de novembro de 2013

Versão final apresentada em 1 de setembro de 2014

Aprovado em 29 de setembro de 2014 